\title{
DOES GESTRINONE ANTAGONIZE THE EFFECTS OF ESTROGEN ON ENDOMETRIAL IMPLANTS UPON THE PERITONEUM OF RATS?
}

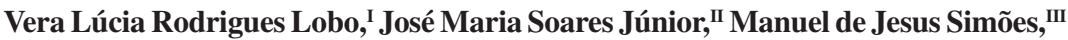

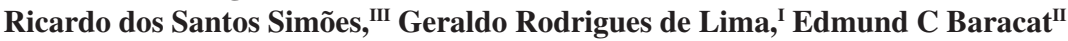

doi: $10.1590 / \mathrm{S} 1807-59322008000400019$

Lobo VLR, Soares Júnior JM, Jesus Simões M, Simões RS, Lima GR, Baracat EC. Does gestrinone antagonize the effects of estrogen on endometrial implants upon the peritoneum of rats? Clinics. 2008;63:525-30.

OBJECTIVE: To evaluate the effects of estrogen treatment in combination with gestrinone on an experimental rat model of endometriosis.

METHODS: Uterine transplants were attached to the peritoneum of female Wistar rats via a surgical autotransplantation technique. The implanted area was measured during the proestrus phase and after hormonal treatment. We performed morphometric analysis and examined the macroscopic and morphometric alterations of endometrial implants after hormonal treatment in ovariectomized rats.

RESULTS: The high dose of estrogen caused macroscopic increases in the endometrial implant group compared with other groups, which were similar to increases in the proestrus phase. The low dose showed morphometric development of implants, such as an increase in number of endometrial glands, leukocyte infiltration and mitosis. Gestrinone antagonized both doses of estrogen.

CONCLUSION: Our findings suggest that gestrinone antagonizes estrogen's effects on rat peritoneal endometrial implants.

KEYWORDS: Experimental endometriosis. Peritoneal implants. Ovariectomized rats. Gestrinone. Estrogen.

\section{INTRODUCTION}

Endometriosis is a clinical and pathological entity that was initially described by Rokitanski in $1860 .^{1}$ Endometriosis is characterized by the presence, outside the uterine cavity, of tissue resembling functioning endometrial glands and stroma. Sampson was responsible for the classification of this affliction as a non-neoplasic disease in 1925. ${ }^{2}$ In fact, endometriosis is one of the most enigmatic and problematic maladies affecting women of reproductive age. It is associated with pain and infertility. Although it is

\footnotetext{
${ }^{\text {I }}$ Departamento de Ginecologia, Universidade Federal de São Paulo - São Paulo/SP, Brazil.

II Laboratório de Investigação Médica (LIM-58) da Disciplina de Ginecologia do Departamento de Obstetrícia e Ginecologia da Faculdade de Medicina da Universidade de São Paulo - São Paulo/SP, Brazil.

III Departamento de Morfologia, Universidade Federal de São Paulo - São Paulo/SP, Brazil.

Email: jsoares415@hotmail.com

Received for publication on February 26, 2008

Accepted for publication on April 16, 2008
}

not a malignant disorder, endometriosis exhibits cellular proliferation, cellular invasion and neoangiogenesis. ${ }^{3}$ Endometriosis is most commonly observed over visceral and peritoneal surfaces within the female pelvis. Despite being one of the most frequently encountered gynecological diseases, the pathophysiology of this disease remains poorly understood. ${ }^{4}$ In addition, ethical considerations limit options for controlled experiments, and it is not possible to monitor the disease progression without performing repeated laparoscopies. Thus, research into the fundamental mechanisms (e.g. mechanisms by which menstrual endometrium adheres, invades and establishes a functional vasculature to persist in an ectopic site), as well as into new therapeutic approaches, is best performed in experimental animal models. ${ }^{5}$

Because menstrual shedding is a requirement for the spontaneous development of this disease, endometriosis occurs naturally only in humans and some non-human primates. Non-human primates have been extensively used for the investigation of endometriosis; however, the very 
high costs of animal handling limit the use of primates as an experimental model. For this reason, experimental models for endometriosis have recently been developed in small laboratory animals, especially rodents, by the transplantation of pieces of endometrial tissue to ectopic sites. ${ }^{5}$

Endometriosis in rats can be induced by transplanting endometrial tissue to ectopic sites. These models are classified into two types, homologous and heterologous models. Homologous models have been employed using the surgical transplantation of endometrium of the same or syngeneic animals, whereas in heterologous models, human endometrial fragments are transferred either intraperitoneally or subcutaneously to immunodeficient mice. ${ }^{5}$

Autotransplantation of uterine tissue to ectopic sites of small laboratory animals has been established not only in rats ${ }^{6-8}$ but also in other models. ${ }^{9,10}$ Of these non-primate models, mainly the rat and mouse models have been extensively developed in recent years. In these models of endometriosis, uteri are removed and cut into small pieces, which are then reintroduced, mostly by suturing, into the peritoneal cavity. In most of these studies, the endometrium was not separated from myometrium; thus, both compartments were implanted. ${ }^{9}$ In the rat, the uterine tissue develops into fluid-filled, ovoid, cystic structures composed of myometrial and endometrial tissue. The cysts grow but stabilize in size by two months and remain viable for at least ten months. ${ }^{11}$ Autotransplanted uterine tissue in the rodent model shows steroid hormone dependency, and thus, this model has been widely used for determining the responsiveness of ectopic lesions to steroid hormones as well as to drugs interfering with steroid action. Comparable to the situation in humans, the growth of the ectopic endometrial tissue in both rodent species was shown to be estrogendependent. ${ }^{10,11}$ In rats that were ovariectomized three weeks after engrafts of uterine tissue, the ectopic fragments recovered much better in animals treated with estrogen alone after ovariectomy than in those with combined estrogen and progesterone treatment. ${ }^{12}$ Fang et al. (2004) ${ }^{13}$ confirmed the important role for estrogen as a factor determining the size of the implants in mice and demonstrated that the anti-proliferative effect of progesterone on the estrogendependent growth of endometrial tissue is mediated by an intact progesterone receptor, because this estrogendependent growth could be suppressed by progesterone in uterine tissues of wild-type, but not of progesterone receptordeficient mice.

Similar to the situation in humans, the regression of uterine ectopic implants could be induced in rats by generating a hypoestrogenic state, for example, by the application of GnRH agonists,,${ }^{14}$ by synthetic progestational compounds such as levonorgestrel or dienogest ${ }^{15,16}$ or by danazol treatment. ${ }^{17}$ Similar effects could be achieved in this model by reducing the estrogen concentration by the application of anti-estrogens, by using the selective estrogen receptor modulator raloxifen, ${ }^{18}$ by treatment with aromatase inhibitors that interfere with estrogen synthesis, or by ovariectomy. ${ }^{14}$

Various authors have reported many complications and side effects of the hormone therapy (HT) on postmenopausal women. ${ }^{19,20}$ In addition, there is a risk of endometriosis recurrence in ovariectomized women who have had peritoneal endometriosis and received estrogen replacement. ${ }^{19}$ Therefore, this hormone should be administered with progestagen to avoid this risk.

Gestrinone, a progestagen (tri-enic steroid) with antiestrogen properties, presents good results for endometriosis treatment during menarche. ${ }^{21}$ Few studies have evaluated gestrinone in animal models. Some of these were done in rabbits ${ }^{22,23}$ and one report used gestrinone in rats with intact ovaries. ${ }^{24}$ Yet, the effectiveness of this drug with an exogenous low or conventional dose of estrogen remains unclear. Thus, the aim of this study was to evaluate the gestrinone-with-estrogen effects on endometrial implants in ovariectomized rats.

\section{MATERIAL AND METHODS}

One hundred and forty rats (Rattus norvegicus albinus) of the EPM-1 Wistar strain at 3 months of age were used, and their average weight was 200 grams. The animals were supplied by the Center for the Development of Experimental Models in Medicine and Biology (CEDEME) of the Federal University of São Paulo - Escola Paulista de Medicina (UNIFESP-EPM). This project received approval in advance from the ethics and research committee of the Federal University of São Paulo.

The animals were transported to the Histology and Structural Biology Biotery of the Morphology Department of UNIFESP-EPM, where they were confined to plastic cages that were $45 \times 30 \times 15 \mathrm{~cm}$ each in length, width, and height, respectively, and had lids made of metal grids. The rats were fed ad libitum. Room temperature was maintained at $22^{\circ} \mathrm{C}$ and artificial lighting was obtained with fluorescent lamps (a 40-watt-daylight Phillips model). The animals were maintained on a standard diet, free from any soybean compounds, and were provided tap water ad libitum.

\section{Rat Endometriosis Induced by Uterine Autotransplan- tation and Laparotomy}

The endometriosis model was generated using female rats with normal estrous cycle maintained on a schedule of 
14 hours of light and 10 hours of dark during the experiment. The guidelines approved by the local institution for the care and use of the animals were followed.

The technique was previously described in detail, ${ }^{12}$ following the protocol described by Jones. ${ }^{15}$ Briefly, at the time of surgery, the animals were anesthetized with xylazine $(20 \mathrm{mg} / \mathrm{kg})$ and ketamine $(100 \mathrm{mg} / \mathrm{kg})$ and their abdomen was shaved; they were submitted to sterile preparation, and opened with a $1.5-\mathrm{cm}$ lower mid-line incision. A cranial segment from the left uterine horn, 4-cm long, was resected. Adequate hemostasis was performed with $6 / 0$ nylon suture. The uterine segment was promptly immersed in sterile isotonic saline at $4^{\circ} \mathrm{C}$, opened by longitudinal incision and fragmented into $5-\mathrm{mm}$ square pieces. Two such uterine pieces were then fixed with $6 / 0$ nylon suture to the abdominal wall on blood vessels, next to the median suture. The tissues were continuously irrigated with sterile isotonic saline to avoid desiccation. The abdominal incision was then closed in two layers using $3 / 0$ polyglycolic acid threads for the muscle and abdominal fascia, and 3/0 silk threads for skin closure. No treatment was given during the postoperative period.

All animals were subjected to daily vaginal smears to observe the estrous cycle. Four weeks after autotransplantation, a second laparotomy was performed in order to measure the sizes (length and width) of implants and to ovariectomize the rats during the proestrus phase (baseline). The rats with unsuccessful induction or irregular estrus cycle were excluded $(n=20)$. Three weeks later (time by which the atrophy of the implants was expected to occur), all animals ( $\mathrm{n}=120)$ were randomly divided into six treatment groups: GI - propylenoglycol (vehicle); GII $17 \beta$-estradiol $(50 \mu \mathrm{g} / \mathrm{kg})$; GIII - $17 \beta$-estradiol $(10 \mu \mathrm{g} / \mathrm{kg})$; GIV - gestrinone $(0.25 \mathrm{mg} / \mathrm{kg}) ; \mathrm{GV}$ - $17 \beta$-estradiol $(50$ $\mu \mathrm{g} / \mathrm{kg})$ with gestrinone $(0.25 \mathrm{mg} / \mathrm{kg}) ; \mathrm{GVI}-17 \beta$-estradiol $(10 \mu \mathrm{g} / \mathrm{kg})$ with gestrinone $(0.25 \mathrm{mg} / \mathrm{kg})$. The drugs were given subcutaneously. Gestrinone was administered every 48 hours. After a 24-day treatment period, the animals were sacrificed; the implanted peritoneal tissue was measured and collected along with abdominal muscle. The material was sectioned, fixed and processed for study by light microscopy. During microscopic evaluation, the investigator was blinded to the status of the previous growth of the implants and the treatment groups.

\section{Light Microscopy Analysis}

The tissue samples from the implanted area were fixed with $10 \%$ buffered formalin and, after routine dehydration, were embedded in paraffin. Sections $(5 \mu \mathrm{m}$ thick) were stained with hematoxylin and eosin (HE) and Masson's trichrome; we used a light microscope (Axiolab, Carl Zeiss) under 100- to 400-fold magnification that was attached to an image capturing system (Axionvision, Carl Zeiss). The morphometric analyses were done to determine the effect of drugs on the glandular epithelial thickness, number of glands, leukocyte infiltration and extent of mitosis.

The average value of the morphological analysis of each parameter was calculated from data of eight endometrial implant sections of each animal. The endometrial thickness index $(\mathrm{ETI})$ was calculated using the formula: $\mathrm{ETI}=2 \mathrm{~A} /(\mathrm{P} 1$ + P2). ${ }^{25}$ The number of glands and leukocytes was evaluated using the Weibel chamber of 25 hits. For each animal, 40 microscopic fields were analyzed using a $100 \mathrm{x}-400 \mathrm{x}$ objective. The mitosis countings were based on the number of typical mitoses in 1.000 epithelial cells per section. The averages of endometrial glands, leukocytes and mitosis were determined by counting all structures of every uterine crosssection. Two independent investigators measured the total uterine and endometrial areas on two separate occasions.

\section{Statistical analysis}

Results were analyzed by one-way analysis of variance and the Tukey-Kramer multiple comparisons test, using 2.01 version GraphPad InStat ${ }^{\mathrm{TM}}$ software. The differences were considered statistically significant when $P<0.05$. The paired Student's $t$-test was also used for comparing the baseline (proestrus phase) with the treatment period data.

\section{RESULTS}

\section{Implant area}

The areas of implants were calculated in all animals before ovariectomy and after treatment, except for GI (Table 1). In this group, no fragment of the implanted endometrium could be measured after treatment because of implant atrophy. The identification of the implant in GI was based upon the suture threads at the end of the experiment. The mean area of GII after treatment (high dose of estrogen) presented the highest values $(\mathrm{p}<0.01)$ of all groups. However, the GII size was similar to baseline (during the proestrus phase). The GIII, GIV, GV and GVI areas were lower than the respective baseline areas. The rat weights are summarized in Table 1. There were no weight differences among the groups in baseline versus after the treatment.

\section{Light Microscopy Analysis}

Histopathologically, the GI implants showed only connective tissue and cells with different shapes. The cells 
Table 1 - Rat weight and implant area of the endometrial implants (mean + S.E.M.) before ovariectomy (baseline) and after treatment

\begin{tabular}{lcccccccccccccc}
\hline & \multicolumn{2}{c}{ GI } & \multicolumn{2}{c}{ GII } & \multicolumn{2}{c}{ GIII } & \multicolumn{2}{c}{ GIV } & & \multicolumn{2}{c}{ GV } & \multicolumn{2}{c}{ GVI } \\
& RT & IA & RT & IA & RT & IA & RT & IA & RT & IA & RT & IA \\
\hline Baseline & 219.6 & 32.8 & 221.3 & 29.2 & 230.2 & 33.5 & 213.6 & 33.1 & 239.6 & 28.9 & 219.6 & 31.1 \\
& \pm 19.2 & \pm 2.5 & \pm 22.8 & \pm 2.6 & \pm 11.9 & \pm 4.1 & \pm 29.8 & \pm 2.8 & \pm 31.4 & \pm 4.2 & \pm 15.8 & \pm 2.7 \\
\hline After treat- & 220.5 & $*$ & 229.1 & 34.9 & 211.5 & 6.9 & 225.5 & 3.5 & 232.5 & 4.4 & 231.5 & 4.0 \\
ment & \pm 33.6 & & \pm 24.7 & $\pm 3.6^{\mathrm{a}}$ & \pm 29.1 & $\pm 2.9^{\mathrm{b}}$ & \pm 29.9 & $\pm 1.5^{\mathrm{b}}$ & \pm 37.7 & $\pm 1.5^{\mathrm{b}}$ & \pm 23.6 & $\pm 1.3^{\mathrm{b}}$ \\
\hline
\end{tabular}

RT = Rat weight $(\mathrm{g}) ; \mathrm{IA}=$ Implant area $\left(\mathrm{mm}^{2}\right) ; *$ = atrophic implants, only recognized by the surgical nylons. a) p<0.01 compared to GIII, GIV, GV and GVI after treatment; b) $\mathrm{p}<0.01$ compared to baseline

Table 2 - Morphometric analyses of the endometrial implants after treatment

\begin{tabular}{lcccccc}
\hline & \multicolumn{5}{c}{ Implant area $\left(\mathrm{mm}^{2}\right)$} \\
\cline { 2 - 7 } & GI & GII & GIII & GIV & GV & GVI \\
\hline Glandular epithelial Thickness $(\mu \mathrm{m})$ & NM & $16.3 \pm 0.5^{\mathrm{a}}$ & $10.2 \pm 0.6$ & $8.6 \pm 0.6$ & $10.1 \pm 0.8$ & $9.1 \pm 0.4$ \\
Endometrial glands $(\mathrm{n})$ & $\mathrm{NM}$ & $88.1 \pm 3.8^{\mathrm{a}}$ & $22.9 \pm 3.1^{\mathrm{b}}$ & $11.2 \pm 0.8$ & $16.5 \pm 0.8$ & $10.7 \pm 1.1$ \\
Leukocytes $(\mathrm{n})$ & $\mathrm{NM}$ & $30.1 \pm 2.3^{\mathrm{a}}$ & $11.4 \pm 1.4^{\mathrm{b}}$ & $2.1 \pm 0.4$ & $4.5 \pm 1.3$ & $2.0 \pm 0.6$ \\
Mitosis figure $\left(10^{-3}\right)$ & $\mathrm{NM}$ & $26 \pm 2^{\mathrm{a}}$ & $12 \pm 1^{\mathrm{b}}$ & $3 \pm 1$ & $5 \pm 1$ & $1 \pm 1$ \\
\hline
\end{tabular}

$\mathrm{NM}=$ non measured; a) $\mathrm{p}<0.01$ compared to other groups; $\mathrm{b}$ ) $\mathrm{p}<0.05$ compared to GIV, GV and GVI

presented picnotic and heterochromatic nuclei in close contact with skeletal muscle fibers. No endometrial glands were identified. Table 2 summarizes the morphometric results. The high dose of estrogen group (GII) presented more well-developed endometrial implants than did the other groups.

\section{DISCUSSION}

Consistent with other studies, the macroscopic and microscopic results in vehicle- and estrogen-treated groups confirmed the hormone-dependent nature of the experimental implants. ${ }^{6-12}$ The low dose of estrogen did not macroscopically stimulate growth of the implants. However, there was evidence of estrogenic action upon light microscopy examination, namely an increase in endometrial glands, leukocyte infiltration and mitosis. In addition, gestrinone antagonized both doses of estrogen in ovariectomized rats. Although gestrinone and estrogen are steroids that may affect body weight, ${ }^{26}$ we did not find significant differences in weight among our groups.

There is a small incidence of endometriosis in postmenopausal women, and only $2-4 \%$ of the laparoscopies of patients with endometriosis are performed in the postmenopausal period. ${ }^{27}$ Only a few investigations have examined the incidence of endometriosis in postmenopausal women and the relationship of the disease with hormonal replacement. Controlled post-menopausal endometriosis studies, as well as studies of the course of the disease under hormonal replacement conditions, are very difficult to carry out. Therefore, the rat experimental model is important for analyzing the estrogen and gestrinone effects on endometrial implants. Overall, this study demonstrated many morphological features of this model that may be useful for investigation of endometriosis. ${ }^{13}$

Some studies have demonstrated implant proliferation with estrogen treatment in ovariectomized rats. ${ }^{10-12}$ However, much of the discussion on the use of hormone replacement refers to what might be the minimal dose for obtaining benefits. In fact, many authors report that a low-dose estrogen replacement would have advantages with minimum side effects or complications in contrast to the classic estrogen replacement therapy. Nevertheless, this low-dose estrogen protocol is controversial..$^{28,29}$ To address this issue, a previous study (data not shown) in our laboratory used a conventional dose of estrogen dose in the same experiments. Macroscopically, this higher dose produced endometrial implant growth and development, similar to what is seen in proestrus phase (high estrogen levels during the estrous cycle). The low-dose estrogen treatment during the first month presented lower stimulation of the endometrial implants than did the metaestrus phase (low estrogen levels). In this study, the low dose showed microscopic signals of endometrial implant proliferation (Table 1). This is important since many authors have suggested that onehalf the usual dose of estrogen hormone therapy could be safe for maintaining bone mass with minimum endometrial proliferation. ${ }^{30-32}$ 
Anti-estrogenic effects have been observed with gestrinone.$^{33}$ In addition, this study showed an immunological effect not previously described for gestrinone. The effect of gestrinone may be paradoxical and may be similar to that described for tamoxifen by Kadaba and Simpson. ${ }^{34}$ According to this hypothesis and as supported by our results, gestrinone could exert an anti-estrogenic effect when estrogens are present, ${ }^{35}$ but a partial agonistic effect in the absence of endogenous estrogens. ${ }^{36}$ This result was shown in our study by the macroscopic implant proliferation. The growth of endometrial peritoneal implants was impaired by about $50 \%$ in rats bearing intact ovaries. ${ }^{24}$ The hormonal conditions of the animals we used were diverse, since we used oophorectomized rats, thereby taking advantage of the absence of ovarian steroids which could influence the effect of gestrinone on endometrial growth. In addition, gestrinone antagonized both estrogen doses in our study. This result suggests that estrogen in combination with gestrinone may constitute an alternative treatment for postmenopausal women with endometriosis. However, its side-effects make it unsuitable for long-term use in humans. ${ }^{37}$

Gestrinone effectively antagonized the effects of estrogen on the implant viability in a rat model of endometriosis. This suggests that gestrinone could possibly produce a similar effect in humans, but we must keep in mind that the present results cannot be directly extrapolated to postmenopausal women.

\section{REFERENCES}

1. Wharton Jr LR Endometriosis. In: Mattingly, RF. Te Linde's Operative Gynecology. Philadelphia, J.B. Lippincott Company, 1977. p. 223-52.

2. Sampson JA. Heterotopic or misplaced endometrial tissue. Am. J. Obstet. Gynecol. 1925;10:649-64.

3. Taylor RN, Lebovic DI, Mueller MD. Angiogenic factors in endometriosis. Ann N Y Acad Sci. 2002;955:89-100.

4. Witz CA, Burns WN. Endometriosis and infertility: is there a cause and effect relationship? Gynecol Obstet Invest. 2002;53 Suppl 1:2-11.

5. Grümmer R.Animal models in endometriosis research.Hum Reprod Update. 2006;12:641-9.

6. Golan A, Winston RM, Dargenio R. Experimental endometriosis: a microsurgical animal model in rats.Isr J Med Sci. 1984;20:1094-6.

7. Rajkumar K, Schott PW, Simpson CW. The rat as an animal model for endometriosis to examine recurrence of ectopic endometrial tissue after regression.Fertil Steril. 1990;53:921-5.

8. Sharpe KL, Bertero MC, Vernon MW. Detection of a progesteroneinduced secretory protein synthesized by the uteri but not the endometriotic implants of rats with induced endometriosis.Fertil Steril. 1991;55:403-10.

9. Cummings AM, Metcalf JL. Induction of endometriosis in mice: a new model sensitive to estrogen.Reprod Toxicol. 1995;9:233-8.

10. Rock JA, Prendergast RA, Bobbie D, Green WR, Parmley TH, Dubin $\mathrm{NH}$. Intraocular endometrium in the rabbit as a model for endometriosis. Fertil Steril. 1993;59:232-5.

11. Vernon MW, Wilson EA. Studies on the surgical induction of endometriosis in the rat. Fertil Steril. 1985;44:684-94.

12. Schor E, Baracat EC, Simões MJ, Freitas V, Giannotti Filho O, Lima, GR. Effects of conjugated estrogens and progestogen in surgically induced endometriosis in oophorectomized rats. Clin Exp Obstet Gynecol. 1999;26:158-161.
13. Fang Z, Yang S, Lydon JP, DeMayo F, Tamura M, Gurates B, et al. Intact progesterone receptors are essential to counteract the proliferative effect of estradiol in a genetically engineered mouse model of endometriosis. Fertil Steril. 2004;82:673-8.

14. Kudoh M, Susaki Y, Ideyama Y, Nanya T, Mori M, Shikama H. Inhibitory effects of a novel aromatase inhibitor, YM511, on growth of endometrial explants and insulin-like growth factor-I gene expression in rats with experimental endometriosis. J Steroid Biochem Mol Biol. 1997;63:7580.

15. Jones RC. The effect of a luteinizing hormone releasing hormone (LRH) agonist (Wy-40,972), levonorgestrel, danazol and ovariectomy on experimental endometriosis in the rat. Acta Endocrinol (Copenh) 1984;106:282-8.

16. Katsuki Y, Takano Y, Futamura Y, Shibutani Y, Aoki D, Udagawa Y, et al. Effects of dienogest, a synthetic steroid, on experimental endometriosis in rats.Eur J Endocrinol. 1998 Feb;138:216-26.

17. Sakata M, Terakawa N, Mizutani T, Tanizawa O, Matsumoto K, Terada $\mathrm{N}$, et al. Effects of danazol, gonadotropin-releasing hormone agonist, and a combination of danazol and gonadotropin-releasing hormone agonist on experimental endometriosis. Am J Obstet Gynecol. 1990;163:167984.

18. Yao Z, Shen X, Capodanno I, Donnelly M, Fenyk-Melody J, Hausamann $\mathrm{J}$, et al. Validation of rat endometriosis model by using raloxifene as a positive control for the evaluation of novel SERM compounds. J Invest Surg. 2005;18:177-83.

19. Galhardo CL, Soares JM Jr, Simões RS, Haidar MA, Rodrigues de Lima $\mathrm{G}$, Baracat EC. Estrogen effects on the vaginal $\mathrm{pH}$, flora and cytology in late postmenopause after a long period without hormone therapy. Clin Exp Obstet Gynecol. 2006;33:85-9.

20. Bonduki CE, Lourenço DM, Motta EL, Soares JM Jr, Haidar MA, Baracat EC. Effect of estrogen-progestin hormonal replacement therapy on blood coagulation and fibrinolysis in postmenopausal women. Clinics. 2007;62:553-60.

21. Taylor H, Guarnaccia M, Olive D. Alternative medical treatment for endometriosis. Semin Reprod Endocrinol 1997;15:285-90. 
22. Giu Y, Huang S, Wu X. Effects of gestrinone on experimental endometriosis in rabbits. Zhonghua Fu Chan Ke Za Zhi. 1995;30:7357.

23. Tamaya T, Wada K, Imai A, Mori H, Ban H. Rationale for frequency and dose of administration in gestrinone therapy for pelvic endometriosis in the experimental model of rabbit uterus. Gen Pharmacol. 1991;22:50510.

24. Quereda F, Barroso J, Acién P. Individual and combined effects of triptoreline and gestrinone on experimental endometriosis in rats. Eur J Obstet Gynecol Reprod Biol. 1996;67:35-40.

25. Rossi AG, Soares JM Jr, Motta EL, Simões MJ, Oliveira-Filho RM, Haidar MA, et al. Metoclopramide-induced hyperprolactinemia affects mouse endometrial morphology. Gynecol Obstet Invest. 2002;54:18590.

26. Mayes JS, Watson GH. Direct effects of sex steroid hormones on adipose tissues and obesity. Obes Rev. 2004;5:197-216

27. Punnonen RK, Klemi PJ, Nikkanen V. Postmenopausal endometriosis. Eur J Obstet Gynecol Reprod Biol 1980;11:153-9.

28. Burger HG. Physiological principles of endocrine replacement: estrogen. Horm Res. 2001;56 Suppl 1:82-5.

29. Cotroneo MS, Lamartiniere CA Pharmacologic, but not dietary, genistein supports endometriosis in a rat model. Toxicol Sci. 2001;61:68-75.
30. Lobo RA, Whitehead MI. Is low-dose hormone replacement therapy for postmenopausal women efficacious and desirable? Climacteric. 2001;4:110-9.

31. Rebar RW, Trabal J, Mortola J. Low-dose esterified estrogens $(0.3 \mathrm{mg} /$ day): long-term and short-term effects on menopausal symptoms and quality of life in postmenopausal women. Climacteric. 2000;3:17682.

32. Halaska M, Raus K, Martan A, Voigt R. Hormone therapy and urogynecology. Ceska Gynekol. 1998;63:453-6.

33. Tamaya T, Wada K, Imai A, Mori H, Ban H. Rationale for frequency and dose of administration in gestrinone therapy for pelvic endometriosis in the experimental model of rabbit uterus. Gen Pharmacol. 1991;22:505510 .

34. Kadaba R, Simpson CW. Disparate effect of tamoxifen in rats with experimentally induced endometriosis. Endocrinology. 1990;126:32637.

35. De Leo V, Morgante G, La Marca A, Musacchio MC, Sorace M, Cavicchioli C, et al. A benefit-risk assessment of medical treatment for uterine leiomyomas. Drug Saf. 2002;25:759-79.

36. Shaw RW. A risk benefit assessment of drugs used in the treatment of endometriosis. Drug Saf. 1994;11:104-13.

37. Wingfield M, Healy DL. Endometriosis: medical therapy. Baillieres Clin Obstet Gynaecol. 1993; 7:813-38. 